\title{
As lentes de Barbie Zelizer
}

\author{
Luciana Moherdaui ${ }^{\star}$
}

\begin{abstract}
RESUMO
Este artigo pretende discutir a proposta de Barbie Zelizer ${ }^{* \star}$ apresentada no livro Taking Journalism Seriously, segundo a qual divide os estudos jornalisticos em cinco modelos - sociológico, histórico, lingüístico, politico e cultural. $O$ texto baseiase em teóricos como Tobias Peucer, Adelmo Genro Filho, Jorge Pedro Sousa e Otto Groth, entre outros, mas desconsidera o advento da internet, que alterou significativamente o modo de fazer jornalismo, e o trabalho do sociólogo espanhol Manuel Castells $A$ Sociedade em Rede, que faz uma reflexão sobre o impacto sociocultural e econômico das novas tecnologias de informação e de comunicaçāo do mundo atual.
\end{abstract}

Palavras-chave: teoria, jornalismo, internet

\begin{abstract}
The aim of this article is to discuss the proposal of Barbie Zelizer presented on the book Taking Journalism Seriously, which divide the studies of journalism in five models-Sociological, historical, linguistic, political and cultural. The text is based on theorist such as Tobias Peucer, Adelmo Genro Filho, Jorge Pedro Sousa e Otto Groth and others, but do not take into consideration the internet, which has changed significantly the way in which journalism is made and the work of the Spanish sociologist Manuel Castells, done for the SOCIEDADE EM REDE, in which considers the impact socio-cultural and economic of new technologies of information and communication of the contemporary world.
\end{abstract}

Key words: theory, journalism, internet

\footnotetext{
Mestre em Comunicação e Cultura Contemporâneas pela Faculdade de Comunicação da Universidade Federal da Bahia e editora do portal A Tarde On Line (http://www.atarde.com.br). Autora do primeiro manual de estilo para o jornalismo digital do Brasil - Cuia de Estilo Web - Produção e edição de Noticias On-Line (Senac, 2000) - e uma das responsáveis pela criação do portal ic e do jornal último Segundo.

** Jornalista e professora da cátedra Raymond Williams da Universidade da Pensylvania, nos Estados Unidos.
} 


\section{Introdução}

A reflexão sobre o jornalismo é tradicional nos Estados Unidos desde o século XIX, embora tenha se intensificado principalmente após o célebre livro Public Opinion, de Walter Lippmann, publicado em 1922. Entre 1928 e 1930, o sociólogo alemão Otto Groth lançou em quatro volumes a obra Die Zeitung (O Jornal), resultado de um estudo iniciado em 1910 sobre a compreensão do jornalismo e suas implicações com a sociedade. A teoria de Groth baseia-se em atualidade, universalidade, periodicidade e difusão.

Entretanto, autores como Jorge Pedro Sousa defendem que a tese de doutorado do alemão Tobias Peucer, defendida na Universidade de Leipzig, na Alemanha em 1690, seja a pioneira em teoria do jornalismo. Peucer apontou caminhos para a pesquisa e reflexão que outros autores só começaram a seguir dois séculos mais tarde. $\mathrm{O}$ autor reflete sobre ética "jornalística", relações entre "jornalismo" e história, critérios de noticiabilidade, o papel do mercado na configuração da informação e mesmo sobre agendamento, temas centrais da Teoria do Jornalismo contemporânea ${ }^{1}$.

Notam-se as preocupações de Peucer com algumas das questões em torno das quais se tenta construir atualmente uma teoria da notícia e do jornalismo: os conceitos de notícia e de jornais; as relações entre "jornalismo" e história, a contribuição da retórica e da evolução histórica para a estrutura das notícias, os critérios de noticiabilidade e os constrangimentos à produção 186 de informação.

No inicio do século XIX, adota-se o conceito de quarto poder, no qual jornalismo e democracia confundem-se. Tocqueville afirma que a soberania dos povos e a liberdade de imprensa são inseparáveis. A teoria democrática aponta que o jornalismo deve atuar vigiando os poderes políticos e protegendo os cidadãos, oferecendo informações à sociedade para que os cidadãos possam usar e cobrar serviços públicos.

Em 1947, surge o conceito de gatekeeper, por Kurt Lewin, a partir de um estudo sobre as dinâmicas que agem no interior dos grupos sociais, em especial no que se refere aos programas ligados à modificação dos hábitos alimentares (LEWIN, 1947, p-145). Identificando os canais por onde flui a seqüência de comportamentos relativos a um determinado tema, Lewin nota que existem neles zonas que podem funcionar como cancela, como porteiro: o conjunto das forças antes e depois da zona filtro é diferente de tal forma que a passagem, ou o bloqueio, da unidade através de todo o canal, depende, em grande medida, do que acontece na zona de filtro.

Isso ocorre não apenas com os canais de alimentação, mas também com a seqüência da informação, dada pelos canais de comunicação de um grupo. As zonas de filtros são controladas por sistemas objetivos de regras

\footnotetext{
1 SOUSA, 2004, p. 1-5.
} 
ou por gatekeepers. Neste último caso, há um indivíduo ou grupo que tem o poder de decidir se deixa passar a informação ou se a bloqueia.

Na década de 70, Donald Shaw e Maxwell McCombs formulam outra teoria que marca o campo da produção jornalística: o agenda-setting, segundo a qual os meios de comunicação apresentam ao público uma lista daquilo sobre o que é necessário ter uma opinião e discutir. O pressuposto fundamental do agenda-setting é que a compreensão que as pessoas têm de grande parte da realidade social thes é fornecida pela imprensa (SHAW, 1979, p-96-101).

No Brasil, a primeira defesa sistemática de uma Teoria do Jornalismo só ocorreu na década de 80, com os estudos de Adelmo Genro Filho (1951/ 1988). Genro Filho é autor de $O$ Segredo da Pirâmide, no qual discutiu o jornalismo a partir de aspectos de três grandes correntes: o "funcionalismo norte-americano", a "Escola de Frankfurt" e uma espécie de concepção sobre o jornalismo que se autoproclama marxista, que será chamada de "reducionismo ideológico".

Para abordar o jornalismo como modalidade de conhecimento, são utilizadas três categorias de larga tradição no pensamento filosófico desde a Antigüidade e, em especial, na filosofia clássica alemã: o singular, o particular e o universal. Elas foram aplicadas pelo filósofo húngaro Georg Lukács, com relativo êxito, na formulação de uma estética marxista. Genro Filho as utilizou para a constituição de uma teoria do jornalismo².

A diversidade de autores e perspectivas, no entanto, não significa a existência de uma ampla sistematização da disciplina, objetivo do trabalho de Barbie Zelizer em Taking Journalism Seriously, cujo tema será discutido nos tópicos seguintes. Há poucos estudos classificatórios sobre teoria do jornalismo, mas quase todos são artigos publicados em revistas científicas e não livros estruturados, o que, apesar de atestar seu valor acadêmico, limita o espectro de análise a poucas páginas.

\section{Jornalismo em cinco lentes}

Em Taking Journalism Seriously, Barbie Zelizer propõe uma sistematização que divide os estudos jornalísticos em cinco modelos: sociológico, histórico, lingüístico, politico e cultural. A proposta da autora se justifica pela tentativa de construir uma teoria unificada do jornalismo. Barbie considera o jornalismo como uma instituição muito complexa para poder ser estudada sob uma única lente disciplinar

Sobre o recorte, a autora afirma que as áreas analisadas não privilegiam todos os campos acadêmicos relevantes investidos no estudo do jornalismo como Economia, Antropologia, Direito e Filosofia. Barbie se justifica afirmando que as premissas oferecidas não são excludentes e têm como

2 GENRO, 1987, p, 20-25 
objetivo fornecer uma base comum para a investigação do trabalho jornalístico e estudos de meios de comunicação.

Zelizer alerta para o fato de as fronteiras não serem rígidas e cita como exemplo estudos de Michael Schudson, que tem trabalhos relacionados nas cinco áreas delimitadas. A autoria justifica as citações dos autores pela característica de teoria que trabalham, pois ajudam a focar em dimensões diferentes do jornalismo. Defende a pesquisa de campo [em detrimento do ensaio] como a maneira mais apropriada de fazer essa equalização. Mesmo assim considera a divisão classificatória fundamental para o estudo da Teoria do Jornalismo.

Para a autora, o grande problema da área verifica-se na falta de diálogo entre os jornalistas militantes, que trabalham no mercado, e os jornalistas pesquisadores, cuja atividade está voltada para a reflexão crítica e o ensino. Adelmo Genro Filho já questionara a polêmica teoria versus prática em seu $O$ segredo da pirâmide invertida (1987).

Zelizer acredita ser necessário pesquisar o jornalismo além das lentes da Sociologia, que marcaram tradicionalmente este estudo nos EUA. Usa o conceito de "comunidade interpretativa" na caracterização profissional dos jornalistas, que decorre do seu interesse sobre o que constitui a cultura dos jornalistas e qual a visão dos jornalistas como profissionais.

A obra aplica a proposta de James Carey, referência nos Estudos Culturais norte-americanos, de estudar o jornalismo como um curriculum cujos conteúdos cobrem diferentes tipos de tratamento noticioso, ou como um corpus, cujo significado se prolonga por diferentes tratamentos de um fato em uma organização jornalística.

Procura sair da esfera da pesquisa norte-americana e dar conta de pesquisas em outros lugares, ampliando a atenção aos efeitos da globalização da informação e de suas condições tecnológicas e econômicas, temas já estudados em Journalism After September 11 (2002) e Journalism at War (2004). Entretanto, a influência americana é sentida em todas os modelos de classificações a partir de clássicos como Walter Lippman, Michael Schudson e a socióloga Gaye Tuchman, entre outros.

A autora inicia seu trabalho pela abordagem vertente sociológica, mais utilizada nos EUA. Para Zelizer, a sociologia se ocupa das rotinas produtivas, das organizações, do relacionamento entre grupos e indivíduos, e de todas as demais interações em que estão envolvidos os agentes responsáveis pela captação e pela apresentação das notícias.

Destaca os trabalhos de White (1949) e Breed (1955) como referências clássicas na definição de processos de seleção de acontecimentos que são notícia e das culturas de socialização profissional. Em seguida, o 
estudo de Cohen e Young (1973) The Manufacture of News, que discute a relação jornalista versus fonte de informação e dá atenção aos contrastes entre os códigos de conduta e as práticas de cobertura de guerras, crimes, questões e grupos sociais e destaca a existência de objetivos estratégicos que nâo se relacionavam diretamente com os códigos de objetividade e imparcialidade.

A partir da década de 70 consolida-se o estudo dos efeitos do jornalismo na agenda pública, com as teorias do agendamento, de McCombs e Shaw (1972) em cultivar certas noções da realidade em detrimento de outras (Gerbner e Gross, 1976) ou o que Schudson (2002) chama de efeitos de informação. Segundo Zelizer o periodo intermediário dos estudos sociológicos é assinalado a partir do final dos anos $70 \mathrm{com}$ trabalhos de Tuchman (1978), Gans (1979) e Schlesinger (1978), entre outros. Esses estudos orientam a decisão sobre o que é notícia, as rotinas de classificação e de cobertura dos acontecimentos, sustentação da objetividade, procedimentos ideológicos não expressos pelos jornalistas.

Já a perspectiva histórica tem como foco a longevidade do jornalismo. A autora se apóia na investigação anglo-americana, em particular aos trabalhos de Schudson, sobre o jornalismo norte-americano, e de Curran e Seaton, sobre a mídia britânica. A história depende de documentos e de um afastamento temporal para empreender análises contextualizadas. Por conta disso, Zelizer identifica três momentos na pesquisa: um ponto de partida da história do jornalismo, marcado pela atenção a memórias, biografias, história de organizações jornalísticas; um ponto intermediário, focado na identificação de períodos, temas e acontecimentos marcantes; um momento contemporâneo, voltado à ampliação da história do jornalismo, ao considerá-la indissociável do desenvolvimento do Estado-nação, articulando assim a História com a Ciência Política.

A autora aponta um campo de tensão sobre a maneira como é pensada a investigação histórica por jornalistas e por historiadores. Critica o fato de a análise histórica no estudo do jornalismo ser marcada por perspectivas contraditórias sobre o que é o trabalho da história e o estudo do jornalismo, da comunicação e da história da mídia.

$\mathrm{Na}$ área da linguagem, parte da premissa de que o jornalismo envolve construção, que os textos não são transparentes ou simples, mas construções de interlocutores. Para a autora, a noção da linguagem jornalistica compõe os seguintes elementos: texto, som, imagens e padrões de interatividade. A simples leitura de um texto pode não ser óbvia em nenhum lugar, na realidade, a leitura de um texto é produto de um contingente social, de um processo 
negociado do significado de construção. A leitura envolve necessariamente um exame realçado do texto a partir de um amplo contexto cognitivo, social, cultural, político e econômico. Nesse contexto, estão incluídas a Análise do Discurso e a Semiótica, por exemplo.

Conclui com a pergunta: "O que o estudo das linguagens na notícia ofereceu à investigação do jornalismo?". A principio, a ênfase no texto jornalístico mostra resistência associada ao estudo da linguagem. Enquanto pesquisadores oferecem uma detalhada visão do que parece o texto jornalístico, há também uma tensão no texto sobre o amplo ambiente e o processo no qual o jornalismo é feito.

A quarta categoria é a política, que se interessa fundamentalmente pelo papel que a mídia tem no sistema político. Mas também estão incluídos estudos sobre campanhas eleitorais nas manchetes de jornais e outros veículos, além do agendamento da população e dos próprios atores políticos. $\mathrm{O}$ texto destaca as características essencialmente normativas dessa área e aponta direções sbre o que é o jornalismo e como deveria ser, com variações significativas na escala do olhar analítico.

Zelizer também traz à tona as relações dos jornalistas com as fontes de informação. Estudos como o de Sigal (1973) e de Tunstall (1971) mostraram o predomínio das fontes oficiais, a distinção entre fontes com acesso continuado e as outras, as particularidades de certas coberturas, como o crime. Outro ponto importante é a discussão sobre o papel do jornalista em

190 vários países ocidentais, que permitiu dar conta de variações entre posturas de neutralidade ou participação quanto à inserção política do jornalista (WEAVER, 1998; PATTERSON, 1998).

A última categoria, a cultural, cujo foco na produção de identidades, nos simbolos, valores e demais janelas teóricas correlatas, oferece um amplo painel da atividade jornalística. A investigação sob essa perspectiva dá especial atenção às bases culturais que unem jornalistas a não jornalistas, também envolvidos em atos culturais, de expressão e de representação, e a uma perspectiva de jornalismo e de notícia, que compreende diferentes aproximações com o mundo exterior. Não se restringe a um núcleo duro, que tende a excluir a imprensa que não seja de referência ou a privilegiar os textos em relação às imagens.

A autora conclui o livro respondendo por que se interessa pelo estudo do jornalismo nesta perspectiva cruzada:

Porque o jornalismo não é um conceito que permite uma só interpretação, porque há vários jornalismos e é necessária uma sensibilidade mais interdisciplinar para que os investigadores continuem a traçar e a retraçar essas fronteiras, conforme escreve: "Quanto mais enriquecermos as nossas perspectivas sobre a análise das notícias envolvendo perspectivas alternativas como parte integral do nosso pensamento, mais poderemos 
apreciar o que cada tipo de investigação tem para oferecer e compensar a velha idéia de que um tipo de investigação pode nos dar a resposta que procuramos." (ZELIZER, 2005, p.214).

$\mathrm{Na}$ tentativa de delimitar o estudo do campo jornalístico, Barbie desconsidera teorias importantes do jornalismo difundidas na Itália, França e na Espanha, por exemplo. Em seu trabalho, não define jornalismo e não discute o campo da Comunicação. Donbasch (1987) situa a primeira coleção e distribuição profissional e comercial de noticias para o público na Veneza do século XVI. Na Alemanha, o Nürnberger Nachrichten (Noticias de Nuremberg), escrito a mão, e o Ordinari-Zeitungen, publicado em Augsburgo, merecem destaque ${ }^{3}$.

Muito tempo se passou antes de se chegar às quatro características dos jornais modernos: 1) publicidade; 2 ) atualidade (ou seja, informação que se relaciona com o presente e o influencia); 3) universalidade (sem excluir nenhum tema) e 4) periodicidade (distribuição regular). Já no século XVI os assuntos maravilhosos e assustadores atraíam o maior interesse dos editores. ${ }^{4}$

Os primeiros jornais a aparecerem com regularidade na Alemanha datam do ano de 1609: Aviso, em Wolfenbüttel, e Relation, em Estrasburgo. Pouco depois, surgiram jornais na Holanda (1618), França (1620), Inglaterra (1620) e Itália (1636). O primeiro jornal publicado diariamente foi o Einkommende Zeitung, de Leipzig (1650). Estima-se que as tiragens dos jornais do século XVII eram de cem a duzentos exemplares, ainda que o Frankfurter Journal já tivesse uma circulação de 1,5 mil exemplares em $1680^{5}$.

De lá para cá, a história do jornalismo guarda forte relação com a difusão de novas tecnologias de transmissão, comunicação e informação. $O$ conceito de jornalismo (MURAD, 2001, p. 55) encontra-se relacionado ao suporte técnico e ao meio que permite a difusão das notícias. Daí derivam conceitos como jornalismo impresso, radiojornalismo, telejornalismo e jornalismo digital. O jornalismo é considerado a profissão suplementar das pessoas que reúnem, detectam, avaliam e difundem notícias; ou que comentam os fatos do momento ${ }^{6}$.

O jornalismo e a pesquisa mudaram muito nos últimos dez anos e não há referências sobre tais mudanças. O surgimento da internet e posteriormente da world wide web, que transformaram de forma considerável a prática jornalística, são citados apenas uma vez, na página 162, no capítulo em que se discute política. Apesar de citar Habermas e o conceito da esfera pública ${ }^{7}$, passa ao largo das discussões sobre jornalismo participativo, conforme discutiremos no tópico seguinte.

KUNCZIK, 1997, p. 22

4 lbid, p. 23

Ibid, p. 23

Ibid, p 16

' Para Habermas, esfera pública é o âmbito da vida social em que se realiza uma discussão permanente entre pessoas privadas em um público. 
Entretanto, é importante destacar em seu livro a revisão da literatura (restrita à divisão das áreas), a metodologia adotada pela autora para estudar o jornalismo, a defesa da pluralidade e da legitimidade de visões, elementos que enriquecem o estudo. Outro esforço que merece atenção é a necessidade de a pesquisa reconhecer o jornalismo como objeto, compreender como e por que o jornalismo é produzido, em vez de determinar suas características.

\section{Lentes cruzadas}

A sistematização de Zelizer difere da de autores como Mauro Wolf, Nelson Traquina, Jorge Pedro Sousa e Lorenzo Gomis. Traquina e Sousa defendem que a teoria do jornalismo deve ter como ocupação principal investigar por que as noticias são como são e quais são seus efeitos.

Traquina, um dos mais renomados estudiosos da disciplina, utiliza a noção de campo jornalístico. O professor da Universidade Nova, de Lisboa, cita Pierre Bourdieu, para quem o campo é um "espaço social estruturado em forças polarizadas". Desta forma, usando a metáfora do magnetismo, o campo jornalístico estaria dividido entre dois pólos: o positivo e o negativo. $\mathrm{O}$ primeiro seria o ideológico, aquele que define o jornalismo como um serviço público. Já o segundo seria o pólo econômico, que considera a notícia como um produto comercial. Traquina, no entanto, ainda não considera possível a edificação de uma teoria unificada do jornalismo.

192 Para Sousa, professor associado da Universidade Fernando Pessoa, em Porto, já existe conhecimento suficiente para tal unificação. No artigo Construindo uma teoria do jornalismo, publicado pela revista virtual Recensio (www.recensio.ubi.pt), da Universidade da Beira Interior, em Portugal, ele propõe um modelo baseado em duas equações matemáticas interligadas: a primeira sobre a produção das notícias e a segunda sobre seus efeitos. Elas se referem basicamente aos conceitos do autor expressos na obra As notícias e seus efeitos. Aliás, o paradigma de Sousa é o da notícia como construção social da realidade. As fórmulas que ele sugere têm como objetivo a elaboração de um enunciado com clareza, brevidade e universalidade, princípios básicos de todas as teorias científicas.

O pesquisador italiano Mauro Wolf, no livro Teorias da Comunicação (2002), aborda conceitos claramente identificados com a reflexão jornalística como o gatekeeper, o newsmaking e as rotinas produtivas, conceitos abordados pela sociologia do jornalismo ${ }^{8}$.

Lorenzo Gomis em seu livro Teorias del Periodismo (1991), um clássico mapeamento da área, passa pelas mesmas tendências mencionadas por Zelizer, mas não divide sua obra da mesma forma. Na realidade, o pesquisador espanhol relaciona diversas teorias especificas por meio de uma

${ }^{8}$ WOLF, 2002, p.177-214. 
dialética baseada em perguntas e respostas. A principal delas está registrada no prefácio: "Que deve explicar uma teoria do jornalismo?". A resposta é clara: "Deve explicar como o meio decide o que vai dizer e por quê. Uma teoria do jornalismo deve oferecer um modelo abstrato que permita compreender porque uma notícia é publicada e comentada no lugar de outra, que é escolhida".

Ao que se refere ao jornalismo digital, tema não explorado pela autora, o advento da internet e da web mudou os processos produtivos, a relação com o público e os critérios de noticiabilidade. Clássicos como John Pavlick, Jay David Bolter, Pablo Boczkowski, Javier Echeverría, Roger Fidler, Dan Gillmor, John Fiske, Jim Hall, Javier Diaz Noci, Jo Bardoel e Mark Deuze, entre outros, não são citados no livro. Ao que se refere ao jornalismo participativo, autores que discutiram amplamente o tema como Jay Rosen e David Merrit também não estão incluídos na bibliografia."

Um dos mais importantes estudiosos do jornalismo digital, o pesquisador holandês Mark Deuze em seu artigo What is journalism ${ }^{\prime \prime}$, divide o conceito sobre jornalismo em três partes: 1) Jornalismo como ideologia [jornalistas oferecem um serviço público, jornalistas são neutros, objetivos, imparciais e crediveis, Jornalistas têm autonomia editorial, liberdade e independência, Jornalistas têm senso de imediatismo, Jornalistas têm senso de ética e legitimidade]. 2) Jornalismo e tecnologia: Multimidia; 3) Jornalismo e sociedade: Multiculturalismo.

Deuze afirma que multimídia e multiculturalismo [contato entre as diferenças formas de culturas nacionais e locais - que entende que a cultura não está restrita à etnia, à nação ou à nacionalidade, mas como um lugar de direitos coletivos para a determinação própria de grupos] desafiam a percepção do jornalismo e do modo de fazer jornalismo. $O$ autor critica o fato de que poucos artigos acadêmicos que discutem teoria do jornalismo relacionam a multimídia e o multiculturalismo.

"A literatura geralmente discute o papel do jornalismo civico ou a relação dos jornalistas e empresas de comunicação", critica. Deuze propõe repensar o jornalismo e a identidade dos jornalistas para manter um entendimento conceitual coerente do jornalismo praticado na sociedade contemporânea complexa e em constante mudança.

No artigo, Deuze mostra como a multimídia e o multiculturalismo desafiam potencialmente a visão embutida historicamente no jornalismo. "A sociedade multicultural muda o foco e os valores da noticia", conclui.

Não há também referência alguma sobre a obra do sociólogo espanhol Manuel Castells, autor do clássico $A$ Sociedade em Rede, primeiro volume da

\footnotetext{
${ }_{9}^{9}$ Para saber mais sobre os pesquisadores, ver MOHERDAUI, Luciana. "O Usuário de noticias no jornalismo digital". Dissertação de Mestrado apresentada na Faculdade de Comunicação da Universidade Federal da Bahia, julho 2005. Disponivel em http://jornal.atarde.com.br/Luciana/disserta_revisada.pdf. Acesso 19 fev. 2006.

10 DEUZE, 2005, p. 443, $450-455$.
} 
trilogia $A$ era da informação: economia, sociedade e cultura, lançada entre 1996 e 1998. A obra é composta ainda por $O$ poder da identidade e $O$ fim do milênio. No centro da obra de Castells está a reflexão sobre o impacto sociocultural e econômico das novas tecnologias de informação e comunicação no mundo atual.

$\mathrm{O}$ autor criou o conceito sociedade informacional, segundo o qual designa a forma específica de organização social em que a geração, o processamento e a transmissão da informação transformam-se nas fontes fundamentais da produtividade e do poder, devido às novas condições tecnológicas que emergiram no período histórico considerado.

\section{Lentes do Brasil}

No Brasil, o estudo teórico do jornalismo é recente. Apesar de Barbosa Lima Sobrinho e Luiz Beltrão terem sido os pioneiros, seguidos de José Marques de Melo, Nilson Lage e Cremilda Medina, a primeira defesa sistemática de uma Teoria do Jornalismo só ocorreu na década de 80 , com os estudos de Adelmo Genro Filho (1951/1988). Genro Filho é autor de O Segredo da Pirâmide. Ele discutiu o jornalismo a partir de aspectos de três grandes correntes: o "funcionalismo norte-americano", a "Escola de Frankfurt" e uma espécie de concepção sobre o jornalismo que se autoproclama marxista, que será chamada de "reducionismo ideológico".

194 Para abordar o jornalismo como modalidade de conhecimento, são utilizadas três categorias de larga tradição no pensamento filosófico desde a Antigüidade e, em especial, na filosofia clássica alemã: o singular, o particular e o universal. Elas foram aplicadas pelo filósofo húngaro Georg Lukács, com relativo êxito, na formulação de uma estética marxista. Lukács foi um dos mais importantes pensadores marxistas do século 20. A intenção do autor fora aplicá-las para a constituição de uma teoria do jornalismo. Para Genro Filho, o sociólogo alemão Otto Groth é o pioneiro no pensamento de uma teria do jornalismo baseada em atualidade, universalidade, periodicidade, difusão.

O jornalista e doutor em Ciências da Comunicação, Eduardo Meditsch $^{11}$, da Universidade Federal de Santa Catarina - afirma que a classificação temática não é um assunto pacífico em nossa área e cita proposta de sistematização de quatro autores:

1 - Pereira e Wainberg (1999) definem 14 categorias: Jornalismo Organizacional; Ética do Jornalismo; Ensino do Jornalismo; Direito da Comunicação; História do Jornalismo; Jornalismo Alternativo; Jornalismo e Ciência; Jornalismo e Economia; Jornalismo e Empresa Jornalística; Jornalismo Internacional; Jornalismo e Política; Linguagem e Tecnologia do Jornalismo; Memória do Jornalismo; Teorias do Jornalismo.

\footnotetext{
"MEDITSCH, 2003, p.3.
} 
2 - Elias Machado (2004) propõe oito categorias ou linhas de pesquisa: História do Jornalismo; Teorias do Jornalismo; Análise do Discurso; Produção da Noticia; Recepção; Jornalismo Digital; Teorias da Narrativa; Jornalismo Especializado.

3 - Luiz Gonzaga Motta (2004), professor da Universidade de Brasilia, prefere classificar todas as pesquisas em jornalismo dentro de dois grandes paradigmas: "midiacêntrico" e "sociocêntrico".

4 - Márcia Bennetti Machado (2004), da Universidade Federal do Rio Grande do Sul, propõe nove categorias: 1) História do Jornalismo; 2) Estudos de Linguagem; 3) Produção da Notícia e Processos Jornalísticos; 4) Estudos de Recepção; 5) Jornalismo Digital; 6) Ética e Jornalismo; 7) Jornalismo e Educação; 8) Teorias do Jornalismo; 9) Jornalismo Especializado.

O pesquisador Felipe Pena, da Universidade Fluminense, no Rio de Janeiro, vai além e propõe a sistematização a partir de três vertentes principais: a) conceitos e histórias; b) modelos/ teorias de análise; e c) tendências e alternativas ${ }^{12}$. Em seu livro Teoria do Jornalismo (2005), Pena sintetiza o objeto da teoria em duas questões consideradas básicas: 1) Por que as notícias são como são? e 2) Quais são os efeitos que essas notícias geram?

No primeiro caso, o autor discute a produção jornalistica, aborda conceitos como atualidade, periodicidade, objetividade, já estudados anteriormente por Peucer, Groth e Gomis. Para responder a segunda questão, o autor analisa teorias da comunicação e do jornalismo. Ele traz ao debate a Teoria do Espelho (as notícias são como são porque a realidade assim as determina); a Teoria do Newsmaking (o jornalismo é uma construção social de uma suposta realidade) e a Teoria do Gatekeeper (jornalista filtra a informação), entre outras.

Tal como Zelizer, Pena defende que é a interação entre a diversidade que possibilita a unidade. $\mathrm{O}$ autor apresenta como tendências e alternativas o Jornalismo de Resistência, a Reportagem Assistida por Computador, o Jornalismo Digital, o Jornalismo Comunitário, os Correspondentes em Guerra, o Jornalismo Investigativo, a Imprensa Universitária e o Jornalismo Científico.

Rosa Nivea Pedroso, da Universidade Federal do Rio Grande do Sul (UFRGS), a primeira a lecionar a disciplina Teoria do Jornalismo no Brasil, nos anos 80 , diz que a discussão sobre Teoria do Jornalismo no Brasil iniciou há duas décadas, o que é muito pouco em relação ao tempo dispensado à reflexão e à maturação cientifica.

Para a autora do livro Construção do discurso da sedução, no qual analisa o sensacionalismo, o que falta para se tornar uma disciplina cientifica é a construção epistemológica [reflexão em torno da natureza, etapas e limites do conhecimento humano] dos objetos de investigação próprios do campo do jornalismo.

\footnotetext{
12 PENA, 2005, p.10
} 
Pedroso diz que grande parte da literatura publicada no Brasil não trata dos fundamentos teóricos do jornalismo. Para a professora, esta é uma condição sine qua non para saber se tal livro é de teoria ou de análise ou de crítica. A bibliografia que trata da natureza do jornalismo está mais concentrada, e ao mesmo tempo diluída, em artigos e ensaios publicados em revistas científicas. "Depois da publicação do livro de Genro, a obra de Traquina tem sido utilizada na maioria dos trabalhos sobre Teoria do Jornalismo", disse em entrevista ao Observatório da Imprensa, em agosto de $2005^{13}$.

A professora critica a falta de formulação de novos problemas ao que se refere à teoria do jornalismo. Para ela, geralmente, cada autor realça, escolhe, elege um aspecto sob a perspectiva de uma teoria e faz suas defesas pessoais, o que significa que, na maioria das vezes, não está formulando novos problemas, novas perguntas, isto é, teorizando, pois grande parte das publicações não prima pelo conhecimento dos elementos do jornalismo, pois visa analisar ou criticar o jornalismo de uma perspectiva já dada, de uma tese ou hipótese pré-concebida que se tenta provar.

Pedroso cita como exemplo o livro Os elementos do jornalismo, de Bill Kovach e Tom Rosenstiel:

É um livro que você pode ler do ponto de vista de uma teoria, mas não de todas ou de várias. O livro nos alerta para a perda dos valores que constituem o jornalismo como uma atividade de natureza social e como uma profissão comprometida com a cidadania. $E$ isto você pode encontrar na teoria do espelho, uma teoria geralmente interpretada ao pé da letra, o que a leva a ser a mais criticada e combatida de todas as teorias. Grande parte da literatura hoje filia-se às teorias de ação política pelas quais os autores questionam a legitimidade da imprensa. Não chegam a tratar, por exemplo, de problemas como a relação estrutural entre público, fonte e jornalistas (EBLAK, 2005, p.4).

Para a pesquisadora, tratar de questões estruturais significa pensar o sistema, as relações e os fatores que interagem no processo, pois o jornalismo não é um monolito produtivo nem ideológico.

Observa-se, no atual estado dos estudos, uma grande produção de trabalhos que analisam ou criticam o jornalismo de uma perspectiva teórica, geralmente da análise do discurso ou das teorias da ação politica ou do

\footnotetext{
13 EBLAK, 2005.
} 
agendamento, principalmente daquelas teorias que tratam da relação jornalismo e poder. Mas isto não significa que o conhecimento esteja avançando porque, em geral, a intenção de fundo não é conhecer, mas provar uma tese.

Para Ciro Marcondes Filho, um dos precursores do pensar sobre jornalismo, os objetos teóricos do jornalismo ainda estão sendo tratados pelo prisma da análise crítica da Escola de Frankfurt. Em seu livro O Escavador de silêncios, o autor diz que é preciso estudá-los primeiro pelo prisma da filosofia empirica e depois pelo prisma da linguagem. Seria algo como a análise não pode preceder [ocorrer antes] o conhecimento da coisa.

Pedroso não acredita que o campo jornalístico terá um avanço epistemológico imediato, entretanto, pondera e cita pesquisadores como Eduardo Meditsch e Orlando Tambosi, da Universidade Federal de Santa Catarina, como pesquisadores que prometem lançar um mapa mais nítido da teoria do jornalismo. É preciso, porém, não desconsiderar as mudanças vertiginosas ocorridas com o advento da internet, pois além de Deuze, Benetti, Machado e Pena não há propostas para incluir o jornalismo digital no campo teórico do jornalismo.

Não há mais como ignorar a existência das sociedades informacionais (CASTELLS, 2005, p.57), pois os principais processos de geração de conhecimentos, produtividade econômica, poder politico, militar e a comunicação via mídia já estão profundamente transformados pelo paradigma informacional e conectados às redes globais de riqueza, poder e símbolos que funcionam sob essa lógica.

\section{Referências bibliográficas}

BELTRÃO, Luiz. "Iniciação à filosofia do jornalismo". São Paulo, EDUSP, 1992.

CASTELLS, Manuel. "Sociedade em rede". 6 ed. São Paulo: Paz e Terra, 2002.

DEUZE, Mark. "What is journalism? Professional identity and ideology of journalists reconsidered". London, Sage Publications, 2005.

EBLAK, Luis. "Rumo à reflexão e maturação cientifica". Disponível em: http:/ /www.observatoriodaimprensa.com.br. Acesso em 08 mar. 2006.

MURAD, Michael. "Conceitos de Jornalismo”. Edusp. São Paulo, 1997.

GENRO, Adelmo. "O segredo da pirâmide - para uma teoria marxista do jornalismo". Porto Alegre, Tché, 1987.

GOMIS, Lorenzo. "Teoria del periodismo: como se forma el presente". Barcelona, Paidós, 1991. 
Kucinzk, Michael. "Conceitos de Jornalismo: norte e sul”. São Paulo, EDUSP, 1997.

LAGE, Nilson. "Ideologia e técnica da notícia". Petrópolis, Vozes, 1979.

LIPPMANN, Walter. "Public Opinion". New York. Paperbacks. 1922.

MARQUES DE MELO, José. "Jornalismo Opinativo: gêneros opinativos no jornalismo brasileiro". S.P. Mantiqueira. 2003.

MEDITSCH, Eduardo \& SEGALA, Mariana. "A pesquisa brasileira em jornalismo apresentada nos Congressos da SBPJor, Compós e Intercom (20032004)". Paper apresentado durante o II Congresso luso-brasileiro de estudos jornalísticos. Porto. 2005.

MEDITSCH, Eduardo. "Cinco problemas a superar na pesquisa em jornalismo no Brasil e na América Latina”. In: Forum Nacional de Professores de Jornalismo, 2001. Campo Grande, 11 páginas.

MURAD, Angéle. "O hipertexto eletrônico como base para reconfigurar a atividade jornalistica". Disponivel em www.uff.br/mestcii/angele3.htm. Acesso em 08 mar. 2006.

PENA, Felipe. "Scholars e acadêmicos: uma comparação entre as sistematizações teóricas dos pesquisadores de jornalismo no Brasil e nos

198 Estados Unidos”. In: II Colóquio Brasil - Estados Unidos de Ciências da Comunicação, 2005. Rio de Janeiro, 12 páginas. “Teoria do Jornalismo". São Paulo. Editora Contexto. 2005.

PONTE, Cristina. "Lentes cruzadas na pesquisa em Jornalismo: a proposta de Barbie Zelizer". In: V Encontro dos Núcleos de Pesquisa da Intercom, 2005. São Paulo, 15 páginas.

PEREIRA, Manuel Luís Petrik; WAINBERG, Jacques A. "O estado da arte da pesquisa em jornalismo no Brasil: 1983-1997”. In: Revista FAMECOS Porto Alegre, 1999. Disponível em: http://www.pucrs.br/famecos/pos/revfamecos/ 11/jacques.pdf. Acesso em 08 mar. 2006.

ROSEN, Jay. "What are journalists for?" New Haven. Yale University Press. 1999.

SOUSA, Jorge Pedro. "As notícias e seus efeitos". Coimbra. Minerva. 2000.

SOUSA, Jorge Pedro. Tobias Peucer. P"rogenitor da Teoria do Jornalismo". Biblioteca On-Line de Ciências da Comunicação. Portugal, 2004. Disponivel em http://www.bocc.ubi.pt/pag/sousa-jorge-pedro-tobias-peucer.pdf. Acesso em Acesso em 08 mar. 2006. 
SCHUDSON, Michael. "Discovering the news: a Social History of American Newspapers". New York: Basic Books, 1978.

TRAQUINA, Nelson. "Jornalismo: questões, teoria e estórias". Lisboa. Vega. 1993.

. "Teorias do jornalismo". Florianópolis. Insular. 2004.

TUCHMAN, Gaye. "Making News: a study in the construction of reality". New York. Free Press. 1978

WOLF, Mauro. "Teorias da comunicação". São Paulo: Presença, 1995.

ZELIZER, Barbie. "Taking journalism seriously". Routledge. London. 2004. 
[entracampi"

200 